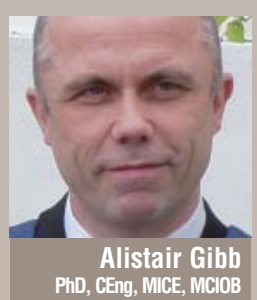

is professor of construction engineering management at Loughborough University

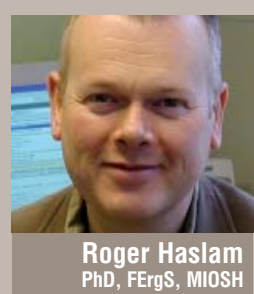

is professor of health and safety ergonomics at Loughborough University

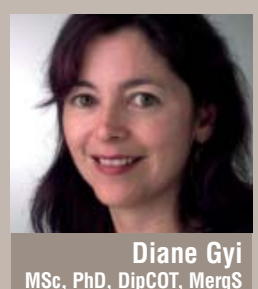

is a senior lecturer in ergonomics at Loughborough University

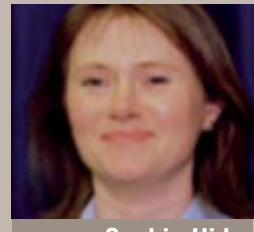

Sophie Hide MSc, PhD

is a former researcher at Loughborough University and now research officer in ergonomics at Massey University, New Zealand

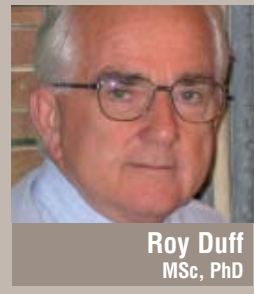

is a construction safety research consultant

\title{
What causes accidents?
}

\author{
This paper describes aspects of the findings of a three-year \\ research project, Construction Accident Causality, funded by \\ the UK Health and Safety Executive. The project developed \\ a causality model, through a combination of focus groups \\ and detailed study of 100 construction accidents, using an \\ ergonomics systems approach, to identify where safety \\ is compromised and why. It concludes that stakeholders \\ responsible for the immediate accident circumstances, shaping \\ factors and originating influences must all work hard to remove \\ flaws in their safety systems to ensure that accidents are reduced.
}

This paper describes aspects of the findings of a three-year research project, Construction Accident Causality (ConCA), ${ }^{1}$ funded by the UK Health and Safety Executive (HSE). ConCA used a combination of focus groups and a detailed study of 100 construction accidents using an ergonomics systems approach, to identify where safety is compromised and why. Other aspects of this major study have been published elsewhere. ${ }^{1-3}$

Although the British construction industry is one of the safest in Europe, one third of all work fatalities occur in construction and construction workers are six times more likely to be killed at work than employees in other sectors. A similar situation exists for non-fatal accidents. Although previous research has led to a good understanding of the extent and pattern of accidents in the construction industry, there has been only limited objective analysis of the full range of contributory managerial, site and individual factors. With this background, ConCA had the following aims.

- To collect rich, detailed data on the full range of factors involved in a large sample of construction accidents.

- Using this information, to describe the processes of accident causation, including the contribution of management, project, site and individual factors in construction industry accidents.

Drawing together the findings, ConCA pro- posed an accident model, illustrating the hierarchy of influences in construction accidents (Fig. 1). The model describes how accidents arise from a failure in the interaction between the work team, workplace, equipment and materials.

These immediate accident circumstances, which relate to the site of the accident or incident, are affected by shaping factors, whereby the actions, behaviour, capabilities and communication of the work team are affected by their attitudes, motivations, knowledge, skills, supervision, health and fatigue. The workplace is affected by site constraints, work scheduling and housekeeping. The suitability, usability, condition and, therefore, safety of materials and equipment depend on their design, specification and supply/availability.

These shaping factors are subject to originating influences, including the permanent works design, project management, construction processes, safety culture, risk management, client requirements, economic climate and education provision. ConCA concluded that achieving a sustained improvement in safety in the industry would require concerted efforts by all stakeholders, directed at all levels in the influence hierarchy.

\section{Relating to other theories}

Many research teams have sought to explain the causes of accidents. Early attempts were somewhat simplistic. ${ }^{4,5}$ More recent efforts 
have acknowledged the complexity of real-life accidents, such as Petersen's human error reduction approach, ${ }^{6}$ Hinze's distractions theory, ${ }^{7}$ Loosemore's chain of events mode ${ }^{8}$ and Suraji et al.'s constraint-response theory. Abdelhamid and Everett's mode ${ }^{10}$ acknowledges complexity but concentrates on site issues only. ${ }^{11}$

In his book Human Error, ${ }^{12}$ James Reason introduces a model to describe the causes of accidents. His work concentrates on major incidents such as Chernobyl, the Challenger space shuttle and London's Kings Cross Underground fire and he argues that most safety systems have a number of layers, or plates. Each of these plates aims to prevent a potential incident passing through them. However, according to Reason, due to human error, none of the plates are impervious-they all have holes. These holes allow the potential incident to pass through the plate, or that layer of the safety system. In most cases, the next layer in the system will intercept the potential incident and prevent its occurrence. However, this next layer also has holes. Reason's theory explains that when holes in all the plates line up, the potential incident becomes a reality-the accident actually occurs. This theory neatly illustrates the role of chance in accident causality. Reason's approach brings in the possibility of multi-causality, as a number of different holes could line up to allow the trajectory of accident opportunity.

While Reason's model was based on major incidents, the authors have applied the approach to the ConCA accident causality results. Thus the plates become the immediate circumstances, shaping factors and originating influences (Fig. 2).

It can therefore be seen that failures by stakeholders responsible for action in each of these three areas can contribute to causing an accident. This approach has received support from a series of workshops involving more than 1000 industry practitioners and has been found to be a useful way of explaining the complex nature of accident causality and the interaction of roles of all the major stakeholders. Efforts made to reduce holes in each of the plates will reduce the chance of accidents occurring, but will never prevent them completely. The ConCA work also identified a compelling reason why designers may feel frustrated by the lack of effect of their efforts to design-out hazards-in many cases, site health and safety practice was so poor that any efforts made by designers and project management teams were being wasted at site level; in other words, using Reason's model, the immediate accident circumstances plate was so full of holes that any hazards not removed pre-site were almost certainly going to result in accidents on site.

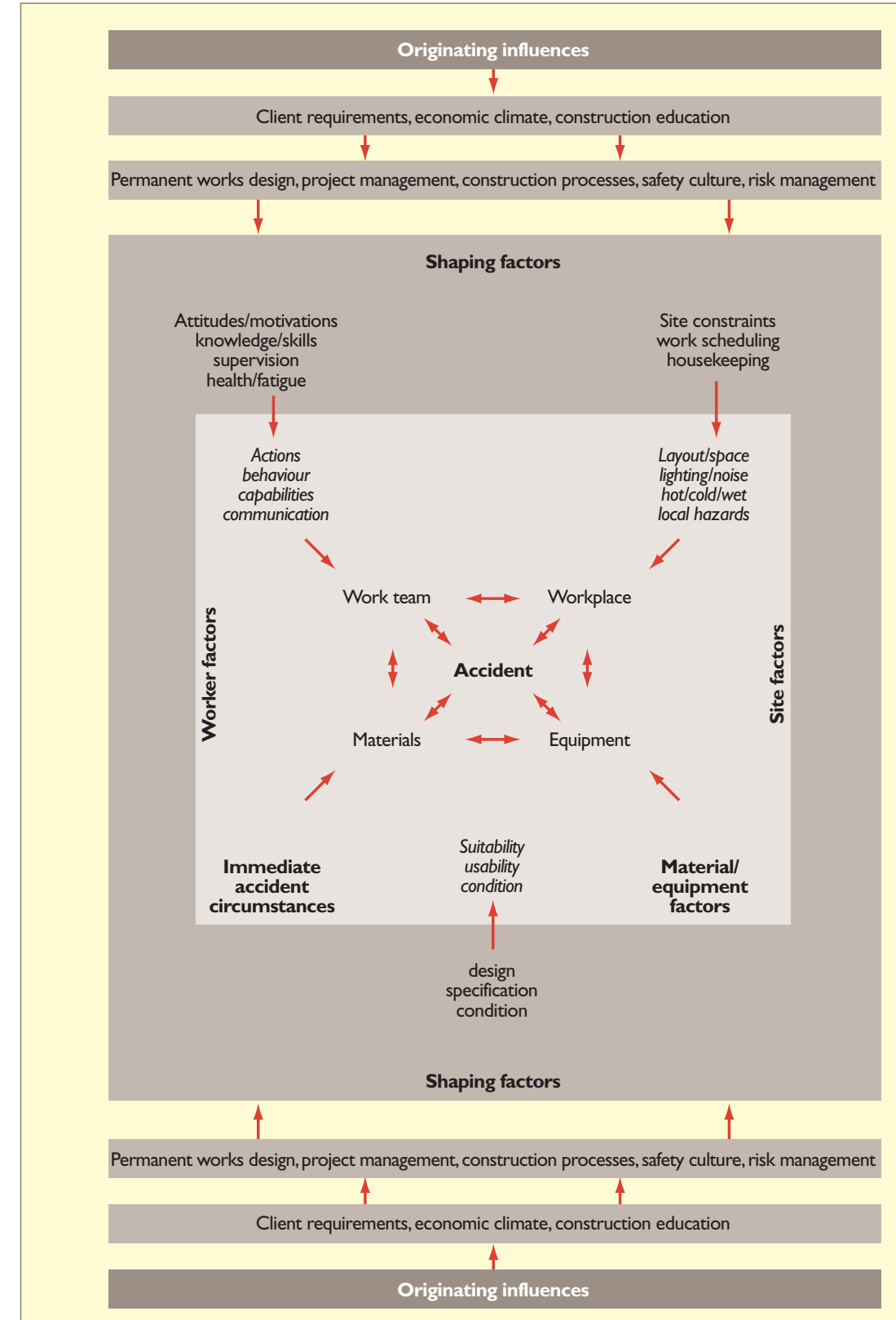

Fig. 1. Loughborough's ConCA accident causality model

Adapting the original ConCA model slightly, the ConCA/Reason model can be used to simplify the message and challenge for the construction industry. The site team, who are largely responsible for the immediate circumstances, need to concentrate on reducing their own holes (i.e. site environment, workplace, worker and tools and equipment issues).

The project management team and detailed designers (the main influencers of the shaping factors) should ensure that they work at the preconstruction planning and design aspects to reduce risk and hence close holes in their

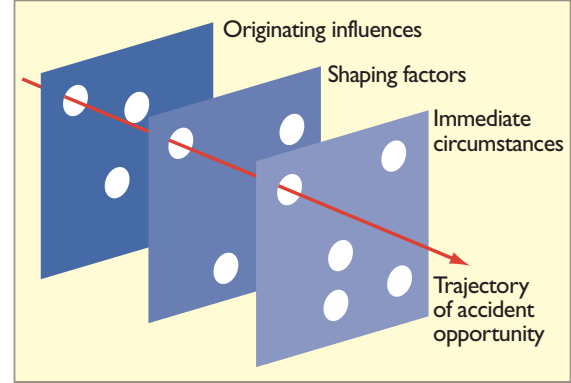

Fig. 2. ConCA model (after Reason ${ }^{12}$ ) 


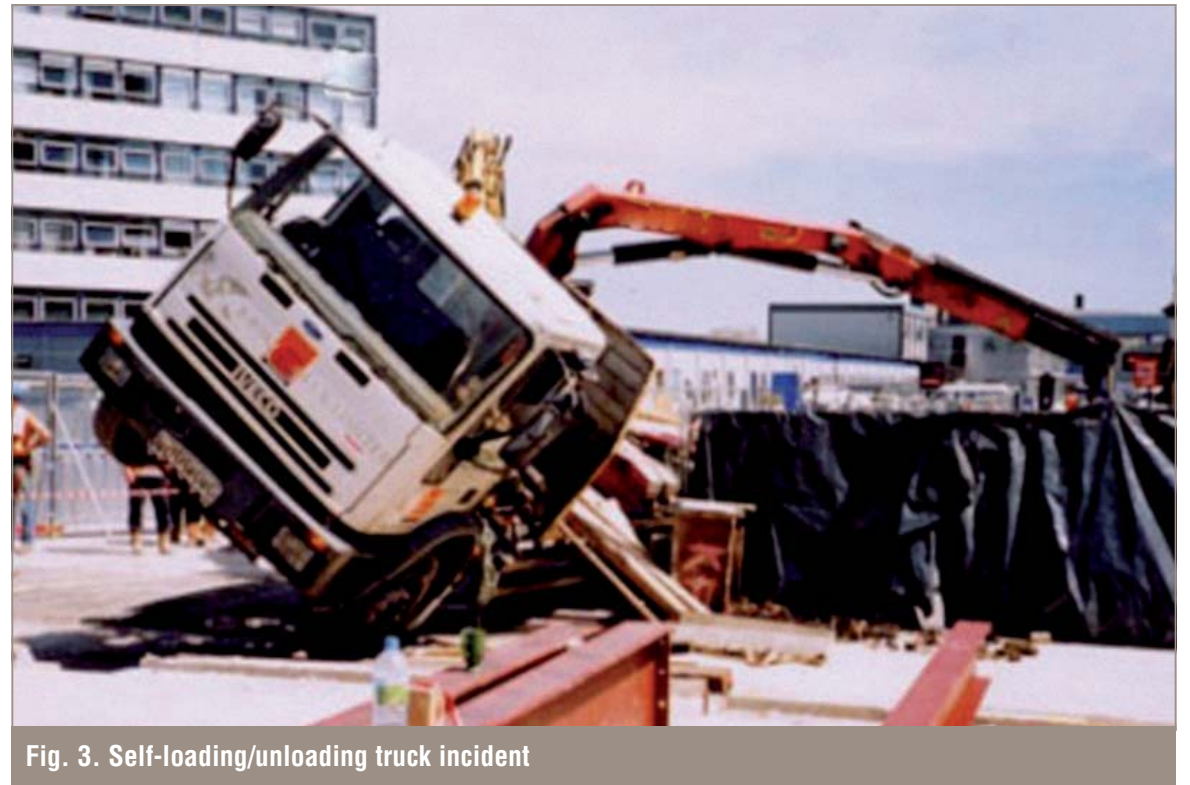

\begin{tabular}{|c|c|c|c|}
\hline & $\begin{array}{l}\text { Immediate accident } \\
\text { circumstances }\end{array}$ & Shaping factors & Originating influences \\
\hline \multirow[t]{5}{*}{ Worker } & \multirow[t]{4}{*}{ Actions } & Fatigue & Culture \\
\hline & & \multirow[t]{3}{*}{ Knowledge/skills } & Management/processes/culture \\
\hline & & & Client requirements \\
\hline & & & Economic climate \\
\hline & Communication & & Risk management (no risk assessment) \\
\hline \multirow[t]{2}{*}{ Site } & Congested work area & Site constraints & $\begin{array}{l}\text { Permanent works design/client } \\
\text { requirements }\end{array}$ \\
\hline & Overlapping trades & Scheduling & Project management/processes \\
\hline \multirow[t]{2}{*}{ Equipment } & \multirow[t]{2}{*}{ Useability } & Design (controls) & \\
\hline & & Design (outriggers) & \\
\hline
\end{tabular}

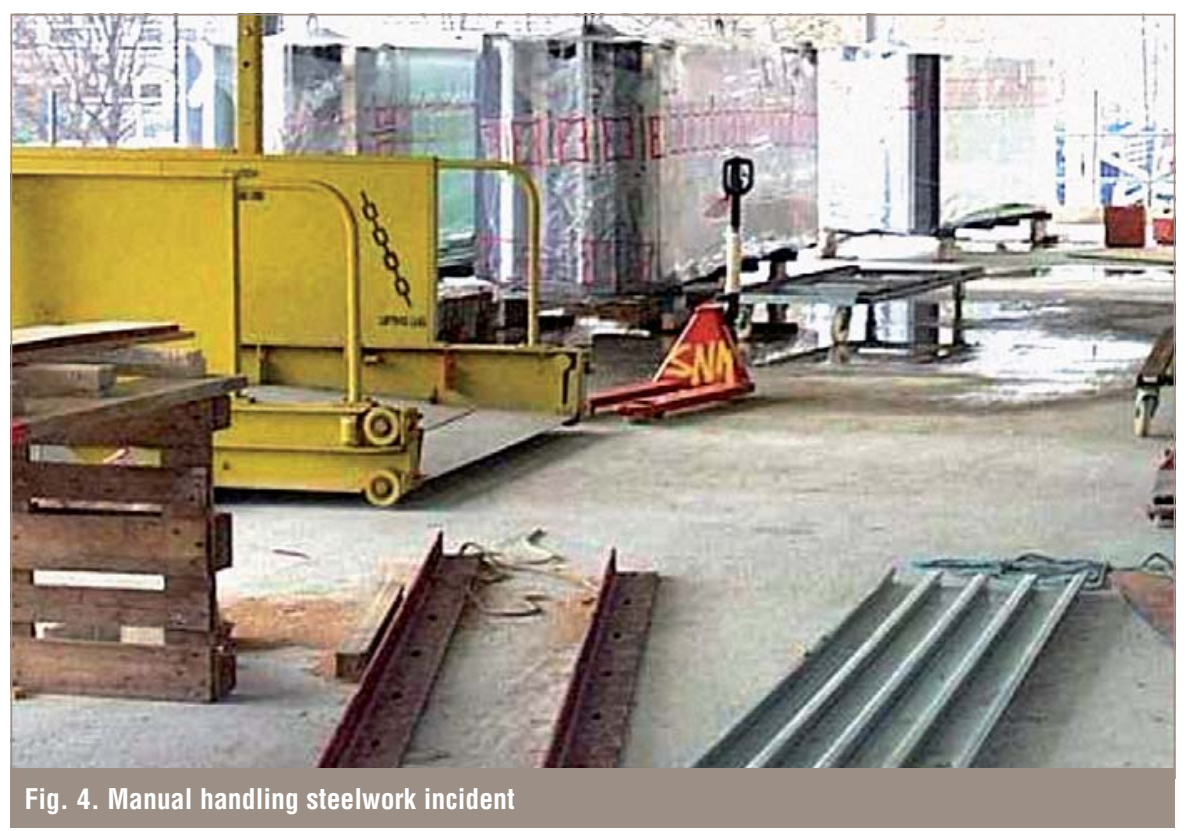

plate. Finally, the client team, concept designers and others who have influence over the industry as a whole can work to reduce risk both at a project and at an industry level. It is only through such a collaborative effort that the number of accidents can be reduced.

\section{Accident studies}

The ConCA model was developed following detailed studies of 100 accidents, to collect further evidence on the issues raised by earlier focus groups. Sampling was on a quota basis, ensuring a spread of accidents across construction build type and RIDDOR accident categories (Reporting of Injuries, Diseases and Dangerous Occurrences - the UK HSE's categories for reporting accidents and incidents). Criteria for inclusion in the study were that the accident was not subject to investigation by HSE, that the accident had occurred within the preceding two months, and that the accident victim and supervisor/manager were still on site and willing to participate in the research.

Site-based data collection entailed interviews with accident-involved personnel and their supervisor or manager, inspection of the accident site and review of relevant documentation, such as accident notification forms, risk assessments and method statements. A report of the site-based findings was reviewed by an expert pairing of construction and ergonomics specialists from the research team which suggested areas for further follow-up examination. Where possible, issues identified were pursued directly with the designers, manufacturers and suppliers relevant to the incident. In many of the studies, however, this proved impossible due to difficulty identifying appropriate individuals to contact and then securing their cooperation. In these cases, the issues were instead discussed with other professionals, independent of the accident but qualified to comment.

Due to the need to avoid incidents subject to HSE investigation, most of the accidents studied were not reportable under RIDDOR. Following assessment of the possible outcomes of each accident, more than a third were judged to have had the potential to cause a fatality and more than two-thirds could have been 'major' as classified under RIDDOR. On this basis, it is argued that it is reasonable to generalise the findings concerning causation from this sample to more serious accidents. Summaries from accident studies are set out below.

Overturning of self-loading/unloading truck

A truck was delivering scaffold to a site. The driver was trying to manoeuvre the load towards the drop zone when the truck tipped over, though no damage was caused (Fig. 3). The stabiliser feet (outriggers) had been put 
down to the ground, but had not been extended beyond either side of the truck beforehand. An analysis of the circumstances, factors and influences is shown in Table 1.

\section{Manual handling steelwork}

Two men of significantly differing heights were moving steel angles by hand. One injured his hand while 'dropping' the angle to the floor (Fig. 4). An analysis of the circumstances, factors and influences is shown in Table 2.

\section{Concrete pump accident}

Concrete-pump pipes were being 'blown through', a cleaning process in which a wet foam ball is placed inside the pipe and is propelled to the other end with pressurised air, at the end of the workday. The accident report states that an operative was standing over the pipe (Fig. 5) and that with the force of propulsion as the last of the concrete and the wet ball came through, this threw him backwards onto a column. He sustained a groin and back injury and was off work for a week. An analysis of the circumstances, factors and influences is shown in Table 3.

\section{ConCA results and implications for} industry

The results of the research of the ConCA project and the implications for industry are summarised as follows.

- Problems arising from workers or the work team, especially worker actions or behaviour and worker capabilities, were judged to have contributed to over twothirds $(70 \%)$ of the accidents. This points to inadequate supervision, education and training.

- Poor communication within work teams contributed to some accidents, due to the physical distance between work colleagues or high levels of background noise.

- Many accidents occurred when those involved were not actually performing a construction task (e.g. moving around site).

Workplace factors, notably poor housekeeping and site layout and space availability problems, were considered to have contributed in half $(49 \%)$ of the accident studies. Standards of housekeeping and workplace layout are low in construction compared to other industrial sectors.

- Despite poor weather often being cited as one of the reasons for construction's poor safety record, ConCA found little evidence in support of this.

- Shortcomings with equipment, including personal protective equipment (PPE), were identified in over half $(56 \%)$ of the incidents. Poor equipment design and inappropriate use of equipment for the task were prominent aspects. Designers, suppliers and purchasers of equipment appear to give insufficient attention to the safety of users.

Deficiencies with the suitability and condition of materials, including packaging, featured in more than a quarter $(27 \%)$ of incidents. The operation of the supply/ purchase chain at present appears to act as a barrier to innovation as far as safety is concerned.

- Originating influences, especially inadequacies with risk management, were considered to have been present in almost all (94\%) of the accidents. Frequently, no risk assessment had been undertaken covering the circumstances involved in the accident. Where a risk assessment had been carried out, it was often found to be superficial and unlikely to have prevented the accident.

- PPE appears to be relied upon habitually as a substitute for risk elimination or reduction at source.

- It was judged that up to half of the accidents could have been mitigated through a design change and it was found that, despite the Construction (Design and Management) Regulations (CDM) ${ }^{13}$ many designers are still failing to address the safety implications of their designs and specifications.

\section{Where a risk assessment had been carried out, it was often found to be superficial and unlikely to have prevented the accident}

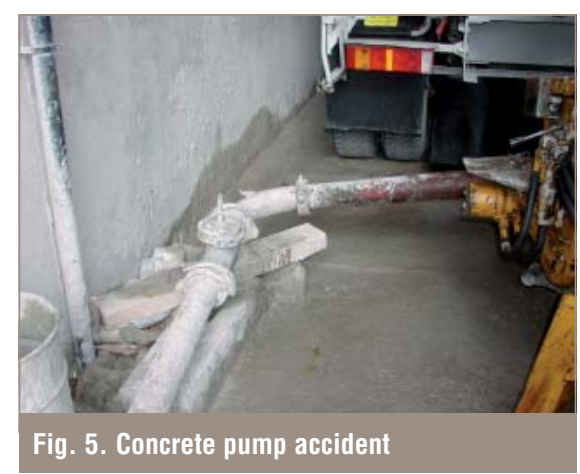

\begin{tabular}{|l|l|l|l|}
\hline \multicolumn{3}{|l}{ Table 2. Analysis of manual handling steelwork incident } \\
\hline & $\begin{array}{l}\text { Immediate accident } \\
\text { circumstances }\end{array}$ & Shaping factors & Originating influences \\
\hline Worker & Actions & Knowledge/skills & Culture \\
\cline { 2 - 4 } & Capabilities & Knowledge/skills & Risk management/processes/culture \\
\hline Site & Congested work area & Site constraints & $\begin{array}{l}\text { Permanent works design/client } \\
\text { requirements }\end{array}$ \\
\cline { 3 - 4 } & & Scheduling & Project management/processes \\
\hline Materials & Useability & Design for handling & Permanent works design \\
\hline Equipment & Suitability & Availability & \\
\hline
\end{tabular}

\begin{tabular}{|c|c|c|c|}
\hline & $\begin{array}{l}\text { Immediate accident } \\
\text { circumstances }\end{array}$ & Shaping factors & Originating influences \\
\hline \multirow[t]{6}{*}{ Worker } & \multirow[t]{2}{*}{ Actions } & Supervision & Management \\
\hline & & Fatigue & Culture \\
\hline & \multirow[t]{3}{*}{ Capabilities } & \multirow[t]{3}{*}{ Knowledge/skills } & Management/processes/culture \\
\hline & & & Client requirements \\
\hline & & & Economic climate \\
\hline & Communication & & Risk management (no risk assessment) \\
\hline \multirow[t]{4}{*}{ Site } & \multirow[t]{3}{*}{ Congested work area } & Site constraints & Permanent works design/client requirements \\
\hline & & \multirow[t]{2}{*}{ Housekeeping } & Project management/culture \\
\hline & & & Client requirements \\
\hline & Overlapping trades & Scheduling & Project management/processes \\
\hline Equipment & Useability & Design & \\
\hline
\end{tabular}


- Accident investigation by employers or supervising contractors was frequently superficial and of little value to improving safety. HSE investigations seem to focus on safety failures in the activity being undertaken, without capturing the upstream influences upon these.

- The influence from clients on safety appeared limited in the construction sectors predominant in this research (civil engineering, major building, residential). This was, again, despite the responsibilities on clients imposed by CDM.

- Many of the incidents were caused by commonplace hazards and activities that will continue to occur on site whatever design changes might be made. The widespread presence of the many generic safety risks accompanying construction needs to be tackled before the benefits of design improvements will be realised.

Together, these factors point to failings in education, training and safety culture in the industry. A large majority of those working in construction, both on and off site, continue to have only a superficial appreciation of health and safety considerations.

\section{Conclusions and recommendations}

Drawing together the findings from the research, an accident model has been proposed (Figs 1 and 2), illustrating the hierarchy of influences in construction accidents. The model describes how accidents arise from a failure in the interaction between the work team, workplace, equipment and materials. These immediate accident circumstances are affected by shaping factors, whereby the actions, behaviour, capabilities and communication of the work team are affected by their attitudes, motivations, knowledge, skills, supervision, health and fatigue.

The workplace is affected by site constraints, work scheduling and housekeeping. The suitability, usability, condition and, therefore, safety of materials and equipment depend on their design, specification and supply/availability. These shaping factors are subject to originating influences, including the permanent works design, project management, construction processes, safety culture, risk management, client requirements, economic climate and education provision.

Achieving a significant and sustained reduction in accidents will require concerted efforts directed at all levels of the hierarchy of causation. Important points are as follows.

- Responsibility for safety needs to be owned and integrated across the project team, from designers and engineers through to skilled trade personnel and operatives.

- Other research has shown how the lead given by front-line supervisors has a strong influence on safety performance. Worker participation in managing safety is important, to generate ideas and to build ownership and responsibility.

- Where safety depends on communication and coordination, it is important that a robust safe system of work is established.

- A step change is required with standards of site layout and housekeeping. Principal contractors should raise expectations of what constitutes acceptable practice.

- Greater attention should be given to the design and selection of tools, equipment and materials. Safety, rather than price, should be the paramount consideration.

- There needs to be greater sophistication with the design and use of PPE. Current PPE is often uncomfortable and impedes performance. Forcing workers to wear PPE when risks are not present may even be counterproductive. PPE should be a last, rather than first, resort for risk management.

- There is a need across the industry for proper engagement with risk assessment and risk management. Emphasis should be on actively assessing and controlling risk, rather than treating risk assessment as merely a paper exercise.

- Construction should be encouraged to benchmark its safety practices against other industries. The excuse that construction is 'different' does not stand up to scrutiny.

- Greater opportunity should be taken to learn from failures, with implementation of accident investigation procedures, both by employers and HSE, structured to reveal contributing factors earlier in the causal chain.

- It is important that 'safety' is disassociated from 'bureaucracy'.

- Frequently, safety does not have to come at a price. Where there are cost implications, however, regulatory bodies and trade associations should work to make sure there is a level playing field.

Most of the changes depend on achieving widespread improvement in understanding of health and safety. Education is needed over training, so as to promote intelligent knowledge rather than unthinking rule-based attention to safety.

Returning to the ConCA/Reason model (Fig. 2), each set of stakeholders must work hard to reduce the flaws in their 'systems' to reduce the likelihood of an upward trajectory of accident opportunity occurring.
References

I. Haslam R. A., HIDE S. A., GIBB A. G. F., GyI D. E., PAVITt T., Atkinson S. and Duff A. R. Contributing factors in construction accidents. Applied Ergonomics, 2005, 36, No. 4, 40I-4l6.

2. GIBB A. G. F., HIDE S. A., HASLAM R. A., GYI D. E., ATKINSON S. and DUfF A. R. Construction tools and equipment-their influence on accident causality. Journal of Engineering Design \& Technology, 2005, 3, No. I, 12-23.

3. Hide S. A., GibB A. G. F., Hastings S., Haslam R. A., GyI D. E., SURAII A. and Duff A. R. By accident or design? Causal factors in construction industry accidents. Proceedings of the International Conference of the European Construction Institute and the CIB Working Commission W99: Designing for Safety \& Health (GIBB A. G. F. (ed.)). ECI, Loughborough, 2000, PP. $45-52$.

4. KERR W. A. Accident proneness of factory departments. Journal of Applied Psychology, 1950, 34, 167-170.

5. HEINRICH H. W. Industrial Accident Prevention: a Scientific Approach, 4th edn. McGraw Hill, New York, 1959. Revised as HeINRICH H. W., Petersen D. and Roos N. Industrial Accident Prevention: a Safety Management Approach, 5th edn. McGraw-Hill, New York, 1980.

6. Petersen D. Human Error Reduction and Safety Management. International Thompson Publishing, New York, 1996.

7. HINZE J. The distraction theory of accident causation. Proceedings of the Ist International Conference of ClB Working Commission W99, Implementation of Safety and Health on Construction Sites (ALVES DIAS \& COBLE (eds)). Balkema, Rotterdam, pp. 375-339.

8. LOOSEMORE M. Psychology of accident prevention in the construction industry. Journal of Management in Engineering, 1998, 13, No. 3, 50-56.

9. Surall A., Duff A. R. and PECKITT S. J. Development of a causal model of construction accident causation. Journal of Construction Engineering \& Management, ASCE, 200I, 127, No. 4, 337-344.

10. ABDelHAMid T. S. and EveretT J. G. Identifying root causes of construction accidents. Journal of Construction Engineering and Management, ASCE, 2000, 126, No. I, 52-60

II. GIBb A. G. F., Hide S. A., HAsLAm R. A. and HASTINGS S. Identifying root causes of construction accidents (discussion). Journal of Construction Engineering \& Management, ASCE, 200I, 127 , No. $4,348$.

12. REASON J. Human Error. Cambridge University Press, Cambridge, 1990.

13. The Construction (Design and Management) Regulations 1994: Elizabeth II Statutory Instrument 1994 No.3140. Her Majesty's Stationery Office, 1994.

\section{What do you think?}

If you would like to comment on this paper, please email up to 200 words to the editor at editor@ice.org.uk. 